\title{
A possible role of a cerebral energy gene in alcoholism
}

\author{
A.F. Ribeiro ${ }^{1}$, D. Correia ${ }^{2}$, R. Boerngen-Lacerda ${ }^{2}$ and A.L. Brunialti-Godard ${ }^{1}$ \\ ${ }^{1}$ Departamento de Biologia Geral, Universidade Federal de Minas Gerais, \\ Belo Horizonte, MG, Brasil \\ ${ }^{2}$ Departamento de Farmacologia, Universidade Federal do Paraná, \\ Curitiba, PR, Brasil \\ Correspondence author: A.L. Brunialti-Godard \\ E-mail: brunialt@ufmg.br
}

Genet. Mol. Res. 11 (1): 404-411 (2012)

Received March 17, 2011

Accepted December 2, 2011

Published February 17, 2012

DOI http://dx.doi.org/10.4238/2012.February.17.2

\begin{abstract}
We examined a possible relationship between genes responsible for energy metabolism of the brain and addictive behavior in an animal model. We used non-inbred, Swiss mice exposed to a three-bottle free-choice model [water, $5 \%(\mathrm{v} / \mathrm{v})$ ethanol, and $10 \%(\mathrm{v} / \mathrm{v})$ ethanol] over a 16 -week period, consisting of four phases: acquisition, withdrawal, reexposure, and quinine-adulteration. The mice were then behaviorally classified into three groups: loss-of-control-drinker (preference for ethanol and high levels of consumption during all phases, $\mathrm{N}=6$ ), heavy-drinker (preference for ethanol and high levels of consumption during acquisition and reduction during quinine-adulteration, $\mathrm{N}=7$ ), and light-drinker (preference for water during all phases, $\mathrm{N}=10$ ). Another group only received tap water (ethanol-naive control mice, $\mathrm{N}=9$ ). Further analysis using quantitative real-time PCR showed that in mice behaviorally classified as loss-of-control-drinkers, there was a significant inverse correlation between transcript levels of the Hadh gene and those of other energy metabolism genes in the nucleus of the amygdala, suggesting that this pathway may contribute to ethanol consumption in these mice.
\end{abstract}


We conclude that cerebral energy metabolism is involved with ethanol addiction, meriting further study.

Key words: Animal model; Brain; Energy metabolism; Ethanol; Extended amygdala

\section{INTRODUCTION}

In the central nervous system there is a dynamic equilibrium between the molecules, which serve as substrate for energy generation. Regardless of the glucose used as the principal source of energy for the brain, it is known that chronic ingestion of ethanol, unlike another alcohol molecules, generates an alternative source of substrate more utilized than glucose, i.e., acetate. Acetate is metabolized into acetyl Co-A, which has an important role in bioenergetic homeostasis in the central nervous system. Furthermore, some proteins and enzymes that act on oxidative phosphorylation and the electron transport process show several regulatory functions, whose effects interfere with signal transduction and neuroplasticity (e.g., response to glucocorticoid stimulus, protein kinase activity, hormone-mediated signaling, regulation of potassium conductance, interaction with brain-derived neurotrophic factor). It means that these molecules are essential for maintaining the equilibrium of cells, neurotransmission and consequently the equilibrium of mental cognitive processes.

\section{MATERIAL AND METHODS}

\section{Animals}

Eighty naive male 6-week-old Swiss mice weighing 20-30 g from the Universidade Federal do Paraná were used in this study. Mice were housed individually $(20 \times 30 \times 20 \mathrm{~cm})$ under a 12-h light/12-h dark cycle (lights on at 7:00) and controlled temperature $\left(22^{\circ} \pm 2^{\circ} \mathrm{C}\right)$, with ad libitum access to food (Purina Laboratory, Curitiba, PR, Brazil). One week before the treatments, mice underwent an acclimation period, and water intake and body weight were measured. All procedures were performed during the light cycle. Experimental care and treatment were approved by the Ethics Committee for Animal Experimentation of the Setor de Ciências Biológicas (Protocol No. 281), Universidade Federal do Paraná.

\section{Animal model procedure}

One group of mice $(\mathrm{N}=60)$ was exposed to three-bottle free-choice treatment for 10 weeks (acquisition phase, AC), during which they had free access to both 10 and $5 \%(\mathrm{v} / \mathrm{v})$ ethanol and water. The positions of the bottles were changed on alternate days when the fluid intake was measured volumetrically. Over the next 2 weeks, only water was provided (withdrawal phase). For the following 2 weeks, the ethanol solutions were again offered to establish free choice among the ethanol solutions and water (reexposure phase, $\mathrm{RE}$ ). At the end of this period, the ethanol solutions were adulterated with $0.005 \mathrm{~g} / \mathrm{L}$ quinine, which creates a bitter-tasting solution, and were offered to the animals for a further 2 -week period (adulteration phase, AD). A separate group of control animals $(\mathrm{N}=20)$ 
only had access to water during all phases of the experiment. At the end of the free-choice ethanol experiment (week 17), mice were euthanized by decapitation, and the extended amygdala brain region was dissected on ice (from both hemispheres; Paxinos and Franklin, 2001). The structures were conditioned in $1 \mathrm{~mL}$ RNAlater ${ }^{\circledR}$ (Ambion-Qiagen, São Paulo, $\mathrm{SP}$, Brazil) and then frozen at $-80^{\circ} \mathrm{C}$.

\section{Molecular analysis}

Total RNA was extracted using TRizol ${ }^{\circledR}$ according to the manufacturer protocol (Invitrogen, São Paulo, SP, Brazil). Samples were quantified using NanoDrop ${ }^{\circledR}$ ND-1000 v3 1.0 (Thermo Fisher Scientific, Waltham, MA, USA). Reverse transcription was performed in a total volume of $20 \mu \mathrm{L}$ using $2 \mu \mathrm{g}$ of total RNA and oligo $\left(\mathrm{dT}_{20}\right)$ primers (Prodimol Biotecnologia, Belo Horizonte, MG, Brazil). SuperScriptIII ${ }^{\circledR}$ (Invitrogen) was used according to the manufacturer protocol. Real-time polymerase chain reaction (quantitative PCR or qPCR) was performed in a Step-One ${ }^{\circledR}$ (Applied Biosystems, Belo Horizonte, MG, Brazil) utilizing SYBR $^{\circledR}$ Green PCR Master Mix (Applied Biosystems, São Paulo, SP, Brazil). To normalize mRNA levels, three reference genes (Gapdh, glyceraldehyde 3-phosphate dehydrogenase; $B$ act, $\beta$-actin; Ppia, peptidylprolyl isomerase A) were used, and the relative quantity (Vandesompele et al., 2002) was calculated for all genes. Only material that was in good condition was used for the molecular analysis, resulting in 9 control mice, 10 light drinker (LD) mice, 7 heavy drinker (HD) mice, and 6 loss-of-control-drinker (A) mice.

\section{Statistical analysis}

Data were analyzed for distribution normality using the Kolmogorov-Smirnov test and homogeneity of variance using the Levene test (analysis of variance [ANOVA]). Body weight in grams and ethanol intake in milliliters were used to compute grams of ethanol intake per kilogram of body weight per day $\left(\mathrm{g} \cdot \mathrm{kg}^{-1} \cdot \mathrm{day}^{-1}\right)$. Repeated-measures ANOVA followed by the Newman-Keuls multiple range post hoc test was performed for each animal's consumption throughout the experimental phases considering the daily consumption for 2 weeks in each phase (i.e., 14 measures in the AC phase, 14 measures in the RE phase, and 14 measures in the AD phase). The $t$-test for independent samples was performed to compare water intake $(\mathrm{mL})$ and total ethanol intake $(\mathrm{mL})$ during the $\mathrm{AC}$ phase for each mouse to detect differences in preference between ethanol and water. These two analyses were performed to classify each mouse as A, HD or LD. The individual data and respective analyses used for classification regarding each mouse are not presented here but were used to allocate mice to their respective groups according to the following criteria: A mice $=$ significant preference for ethanol and high amounts of ethanol consumption during all phases, and maintenance of ethanol consumption (i.e., no significant decrease) during the $\mathrm{AD}$ phase; $\mathrm{HD}$ mice = significant preference for ethanol and high amounts of ethanol consumption during the AC phase and a significant decrease in ethanol consumption during the $\mathrm{AD}$ phase compared with the $\mathrm{AC}$ phase; $\mathrm{LD}$ mice $=$ significant preference for water during all phases (for detailed descriptions, see Fachin-Scheit et al., 2006). The normalized relative quantity of mRNA for all genes was compared using Spearman's correlation. Values of $\mathrm{P}<0.05$ were considered to be statistically significant. Analyses were performed using the STATISTICA 6.1 software (StatSoft, São Caetano do Sul, Brazil). 


\section{RESULTS AND DISCUSSION}

\section{Energy metabolism in the brain: cause or consequence of ethanol exposure}

Using a model where mice were exposed to a free-choice paradigm and later behaviorally classified as one of three phenotypes: A, HD and LD, it was possible to understand the contribution of biological substrate on the development of the persistent ethanol-taking behavior. In this animal model, only mice classified as A continued to ingest ethanol throughout the weeks of treatment without a significant decrease (Fachin-Scheit et al., 2006; Ribeiro et al., 2008; Correia et al., 2009). Interestingly, transcript level analyses in the extended amygdala showed a significant inverse correlation between the Hadh gene (hydroxyacyl-CoA dehydrogenase) and other genes related to cerebral metabolism only in the A group (Table 1). This effect was not observed for the kir channel family member gene (i.e., potassium inwardly rectifying channel) and an enzyme that catalyzes a rate limiting stage for fatty acid synthesis (i.e., long-chain acyl-CoA synthesis), respectively, Kcnj13 (potassium inwardly rectifying channel, subfamily J, member 13), and Acsl1 (acyl-CoA synthetase long-chain family member 1). Additionally, the correlation index between Acsll and Hadh was significant only in the A group $(\mathrm{P}<0.05)$.

Table 1. Transcriptional evaluation for genes involved in energy metabolism in the extended amygdala.

\begin{tabular}{lccccc}
\hline Genes & \multicolumn{3}{c}{ Groups } & \\
\cline { 2 - 5 } & $\begin{array}{c}\text { Control } \\
(\mathrm{N}=9)\end{array}$ & $\begin{array}{c}\mathrm{LD} \\
(\mathrm{N}=10)\end{array}$ & $\begin{array}{c}\mathrm{HD} \\
(\mathrm{N}=7)\end{array}$ & $\begin{array}{c}\mathrm{A} \\
(\mathrm{N}=6)\end{array}$ \\
\hline & & & Hadh & & $-0.93^{*}$ \\
Acaa2 & $0.69^{*}$ & $0.90^{*}$ & & -0.06 & $-0.86^{*}$ \\
Acat1 & $0.71^{*}$ & $0.92^{*}$ & & $0.77^{*}$ & $-0.92^{*}$ \\
Hadhb & 0.56 & $0.86^{*}$ & & 0.52 & $-0.91^{*}$ \\
Kcnn3 & $0.89^{*}$ & $0.83^{*}$ & & 0.74 & $-0.88^{*}$ \\
Sc27a2 & $0.86^{*}$ & $0.91^{*}$ & & -0.47 & 0.41 \\
Kcnj13 & 0.10 & -0.31 & 0.36 & $0.96^{*}$ \\
Acsl1 & -0.37 & 0.13 & & 0.36 & \\
\hline
\end{tabular}

Correlations between mRNA levels of genes in the extended amygdala (Hadh = hydroxyacyl-CoA dehydrogenase; Acaa 2 = acetyl-Coenzyme A acyltransferase 2; Acat1 = acetyl-Coenzyme A acetyltransferase 1; Hadhb = hydroxyacyl-Coenzyme A dehydrogenase; Kcnn 3 = potassium intermediate/small conductance calcium-activated channel, subfamily N, member 3; Slc27a2 = solute carrier family 27, member 2; Kcnj13 = potassium inwardly rectifying channel, subfamily $\mathrm{J}$, member 13 ; Acsl $1=$ acyl-CoA synthetase long-chain family member 1$)$. $\mathrm{LD}=$ light drinker; $\mathrm{HD}=$ heavy drinker; $\mathrm{A}=$ loss-of-control-drinker. Pearson's correlation $(* \mathrm{P}<0.05)$.

Together with other cerebral structures, the extended amygdala region is associated with stimulus contextualization and joins glutamatergic, gabaergic and dopaminergic circuits. This region is involved in choice processing and conditioned reinforcement; soon it will reveal its importance in the development of drug-taking behavior (for review, see Everitt and Robbins, 2005).

Alteration in cerebral mitochondrial metabolism as a consequence of the presence of some fatty acid metabolites might be related to neuropathological processes (Tonin et al., 2010; for review see Cheng et al., 2010). Tonin and co-workers (2010) have demonstrated that the presence of certain types of fatty acid metabolites seems to impair the content of $\mathrm{NAD}^{+}$(nicotinamide adenine dinucleotide) suggesting the existence of an uncoupler effect of the oxidative phosphorylation. Chronically, ethanol metabolism requires the production of fatty acid ethyl esters whose toxicity, among other causes, may be due to the uncoupler effect on the mitochondrial oxidative process 
(Laposata, 1998). The Aldh alleles (i.e., Aldh2(1) and (3), acetaldehyde dehydrogenase gene) that codify enzymes with high affinity for $\mathrm{NAD}^{+}$give more tolerance to ethanol, although the ethanol metabolism rate between selected strains, which possess preference for ethanol, is controversial (e.g., acetaldehyde levels and $\mathrm{NAD}^{+}$). Given that ethanol metabolism depends on NADH levels and that previous soft alterations in the energy metabolism of the organism may cause disturbances in the $\mathrm{NADH} / \mathrm{NAD}^{+}$rate, we might imagine that $\mathrm{ALDH}$ isoforms with more affinity for its prostetic group would be expressed without necessarily increasing the ethanol metabolism rate.

Surprisingly, the proteins codified by Hadh, Hadhb (hydroxyacyl-Coenzyme A dehydrogenase), Acat1 (acetyl-Coenzyme A acetyltransferase 1) and Acaa2 (acetyl-Coenzyme A acyltransferase 2) genes are expressed in the mitochondria indicating their relevance to the emotional equilibrium of the individual. Although SLC27A2 (solute carrier family 27, member 2) carrier does not express in the mitochondria, it does contribute to the transport of certain fatty acids and has the physical potential to interact with the ACAT1 enzyme (von Mering et al., 2002).

The SK3 channel, codified by the Kcnn3 gene (potassium intermediate/small conductance calcium-activated channel, subfamily $\mathrm{N}$, member 3 ), is expressed in the neurons and microglia and it seems to interfere with serotonergic and dopaminergic neurotransmission modulating emotional responses depending on the context (Jacobsen et al., 2008). Its promoter region has a binding site for the transcription factor NFAT (nuclear factor of activated T-cells), whose function is facilitated through mitochondrial calcium flux (Kim and Usachev, 2009). Furthermore, the activation of the SK channel is influenced by modulators of the mitochondrial oxidative phosphorylation process (Fay et al., 2006) and its activity seems also to be modulated by ethanol and proteolipidic content inside the cell (for review, see Mulholland et al., 2009).

The Drosophila melanogaster is utilized as a model for the study of alcoholism and has shown interesting results, perhaps because it is a species that naturally feeds on fermented fruits. Microarray analysis of fruit flies exposed to ethanol has evidenced that lipidic transport genes and fatty acid metabolism genes were altered, including the bubblegum gene (Morozova et al., 2006). Another analysis using adolescent Wistar rats revealed alterations in pathways related to metabolism and/or transport of fatty acid in the brain after chronic ethanol use (Hargreaves et al., 2009). A transcriptome meta-analysis study has found some candidate genes associated with ethanol drinking on murine chromosome nine, among them acyl-CoA synthetase bubblegum family member 1 (Acad11) and acyl-Coenzyme A dehydrogenase family member 11 (Ascbg1) (Mulligan et al., 2006).

We cannot affirm that the alterations (in the transcript levels) found in A mice in our study were previous to ethanol exposure. However, such disturbances indicate that homeostasis of the cerebral energy metabolism is important to the maintenance of persistent drugtaking behavior. Based on our results, we believe that alcoholism has not yet occurred. In other words, the bioenergetic metabolism might be modulating an important neuroadaptation to the preference and "loss of control" in response to ethanol consumption. Despite the metabolic process in the central nervous system revealing new insights into alcoholism, further studies need to be conducted to elucidate the underlying molecular mechanisms that influence the manifestation of these psychiatric disturbances.

\section{Gabab: a gene bubbling over with ethanol addiction}

The principal cells in the central nervous system responsible for energy metabolism are the astrocytes. They also have a close relationship with neurotransmitter bio- 
synthesis, which is important to understanding alcoholism, i.e., glutamate and gammaaminobutiric acid (GABA). Part of glutamate synthesis from GABA in the glial cell by enzyme GABA transaminase (GABA-T) occurs in the mitochondria. Moreover, GABAergic receptors are expressed in these organelles. Considering the communication existing between mitochondria and neural pathways (e.g., energy metabolism, gabaergic, glutamatergic), it would not be surprising if drug-taking behavior involved irregularities in the metabolism of the mitochondria.

The GABAB receptor has special importance in addiction since studies have found that baclofen ( $\beta$-parachlorophenol GABA) reduces relapse into alcoholism in dependent humans and decreases ethanol consumption in Sardinian alcohol-preferring (sP) rats (Addolorato et al., 2002; Colombo et al., 2002; Flannery et al., 2004; Maccioni et al., 2005).

Dzitoyeva and co-workers (2003) have shown that RNA interference for the GABAB1 receptor was capable of reducing the deficit motor caused by ethanol in fruit flies. An association between GABBR1 and GABBR2 and nicotine dependence in a United States population was also found (Li et al., 2009).

A recent study showed alterations in the expression of GABAB1 and GABAB2 subunits and mitochondrial membrane potential decrease after ethanol use in prenatal rat brain (Naseer et al., 2010). Another interesting characteristic of these receptors is their influence on the homeostasis of glucose metabolism (Buck et al., 1997; Eravci et al., 1999; Bonaventura et al., 2008).

Given the emerging need to elucidate the molecular mechanisms of alcoholism neurobiology, additional studies are necessary to clarify the communication involving the activation of the $\mathrm{GABAB}$ receptor in response to signals induced from ethanol addiction behavior.

\section{Perspectives}

The genes related to bioenergetic metabolism in the brain appear to have a critical role in clarifying neurobiological pathways responsible for alcoholism. It is possible that the bioenergetic balance in the central nervous system might have more to do with the maintenance of our emotional states than we imagine. Despite the small effect, the candidate genes have enough potential to alter neural homeostasis, unchaining disequilibrium over neurochemical circuits, which have great relevance for the manifestation of various aspects of human behavior. Still, in the central nervous system, a harmonious relationship is observed between what is transcribed or expressed, at least a good part, like a net. Suggesting that the balance (pre- or post-adaptation to the chronic effects of ethanol) is more dynamic than we might otherwise suppose.

Indeed, identifying genes with small effect is a great challenge. A challenge that involves multiple areas, i.e., experimental, mathematical and statistical knowledge. Such limitations are exacerbated in exploratory or high throughput experiments. However, the study of alcoholism through different animal models can help us to identify genes associated with ethanol consumption and to comprehend the effect of genes considering varied contexts of genic interaction (e.g., free-choice animal model, selected lines or inbreed strains, KO individuals). Maintaining this focus, we will construct the semantic knowledge of the genome and not only its syntactic knowledge. Thus, we will get to explore different aspects of the gene behavior and, consequently contribute to an understanding of the underlying mechanisms of the neurobiology of alcoholism. 


\section{ACKNOWLEDGMENTS}

We thank Maria Rosa Quaresma Bonfim for technical assistance and Oscar Bruña Romero for technical support. The authors also thank Conselho Nacional de Pesquisa (CNPq) and Conselho de Auxilio do Pessoal de Ensino Superior (CAPES) for the fellowships awarded, respectively, to A.F. Ribeiro and D. Correia. Research supported by grants from Minas Gerais State Foundation for Research Support (FAPEMIG: EDT Universal 01/2010, \#APQ-02054-10).

\section{REFERENCES}

Addolorato G, Caputo F, Capristo E, Domenicali M, et al. (2002). Baclofen efficacy in reducing alcohol craving and intake: a preliminary double-blind randomized controlled study. Alcohol Alcohol 37: 504-508.

Bonaventura MM, Catalano PN, Chamson-Reig A, Arany E, et al. (2008). GABA ${ }_{\mathrm{B}}$ receptors and glucose homeostasis: evaluation in GABA receptor knockout mice. Am. J. Physiol. Endocrinol. Metab. 294: E157-E167.

Buck KJ, Metten P, Belknap JK and Crabbe JC (1997). Quantitative trait loci involved in genetic predisposition to acute alcohol withdrawal in mice. J. Neurosci. 17: 3946-3955.

Cheng A, Hou Y and Mattson MP (2010). Mitochondria and neuroplasticity. ASN. Neuro. 2.

Colombo G, Serra S, Brunetti G, Atzori G, et al. (2002). The GABA(B) receptor agonists baclofen and CGP 44532 prevent acquisition of alcohol drinking behaviour in alcohol-preferring rats. Alcohol Alcohol 37: 499-503.

Correia D, Ribeiro AF, Brunialti Godard AL and Boerngen-Lacerda R (2009). Trait anxiety and ethanol: anxiolysis in high-anxiety mice and no relation to intake behavior in an addiction model. Prog. Neuropsychopharmacol. Biol. Psychiatry 33: 880-888.

Dzitoyeva S, Dimitrijevic N and Manev H (2003). Gamma-aminobutyric acid B receptor 1 mediates behavior-impairing actions of alcohol in Drosophila: adult RNA interference and pharmacological evidence. Proc. Natl. Acad. Sci. U. S. A. 100: 5485-5490.

Eravci M, Kley S, Pinna G, Prengel H, et al. (1999). Gene expression of glucose transporters and glycolytic enzymes in the CNS of rats behaviorally dependent on ethanol. Brain Res. Mol. Brain Res. 65: 103-111.

Everitt BJ and Robbins TW (2005). Neural systems of reinforcement for drug addiction: from actions to habits to compulsion. Nat. Neurosci. 8: 1481-1489.

Fachin-Scheit DJ, Frozino RA, Pigatto G, Oliveira GF, et al. (2006). Development of a mouse model of ethanol addiction: naltrexone efficacy in reducing consumption but not craving. J. Neural Transm. 113: 1305-1321.

Fay AJ, Qian X, Jan YN and Jan LY (2006). SK channels mediate NADPH oxidase-independent reactive oxygen species production and apoptosis in granulocytes. Proc. Natl. Acad. Sci. U. S. A. 103: 17548-17553.

Flannery BA, Garbutt JC, Cody MW, Renn W, et al. (2004). Baclofen for alcohol dependence: a preliminary open-label study. Alcohol Clin. Exp. Res. 28: 1517-1523.

Hargreaves GA, Quinn H, Kashem MA, Matsumoto I, et al. (2009). Proteomic analysis demonstrates adolescent vulnerability to lasting hippocampal changes following chronic alcohol consumption. Alcohol. Clin. Exp. Res. 33: 86-94.

Jacobsen JP, Weikop P, Hansen HH, Mikkelsen JD, et al. (2008). SK3 $\mathrm{K}^{+}$channel-deficient mice have enhanced dopamine and serotonin release and altered emotional behaviors. Genes Brain Behav. 7: 836-848.

Kim MS and Usachev YM (2009). Mitochondrial $\mathrm{Ca}^{2+}$ cycling facilitates activation of the transcription factor NFAT in sensory neurons. J. Neurosci. 29: 12101-12114.

Laposata M (1998). Fatty acid ethyl esters: ethanol metabolites which mediate ethanol-induced organ damage and serve as markers of ethanol intake. Prog. Lipid Res. 37: 307-316.

Li MD, Mangold JE, Seneviratne C, Chen GB, et al. (2009). Association and interaction analyses of GABBR1 and GABBR2 with nicotine dependence in European- and African-American populations. PLoS One 4: e7055.

Maccioni P, Serra S, Vacca G, Orru A, et al. (2005). Baclofen-induced reduction of alcohol reinforcement in alcoholpreferring rats. Alcohol 36: 161-168.

Morozova TV, Anholt RR and Mackay TF (2006). Transcriptional response to alcohol exposure in Drosophila melanogaster. Genome Biol. 7: R95.

Mulholland PJ, Hopf FW, Bukiya AN, Martin GE, et al. (2009). Sizing up ethanol-induced plasticity: the role of small and large conductance calcium-activated potassium channels. Alcohol Clin. Exp. Res. 33: 1125-1135.

Mulligan MK, Ponomarev I, Hitzemann RJ, Belknap JK, et al. (2006). Toward understanding the genetics of alcohol 
drinking through transcriptome meta-analysis. Proc. Natl. Acad. Sci. U. S. A. 103: 6368-6373.

Naseer MI, Lee HY and Kim MO (2010). Neuroprotective effect of vitamin C against the ethanol and nicotine modulation of GABA(B) receptor and PKA-alpha expression in prenatal rat brain. Synapse 64: 467-477.

Paxinos G and Franklin KBJ (2001). The Mouse Brain in Stereotaxic Coordinates. 2nd edn. Academic Press, San Diego.

Ribeiro AF, Pigatto G, Goeldner FO, Lopes JF, et al. (2008). Lack of relation between drug-seeking behavior in an addiction model and the expression of behavioral sensitization in response to ethanol challenge in mice. $J$. Neural Transm. 115: 43-54.

Tonin AM, Ferreira GC, Grings M, Viegas CM, et al. (2010). Disturbance of mitochondrial energy homeostasis caused by the metabolites accumulating in LCHAD and MTP deficiencies in rat brain. Life Sci. 86: 825-831.

Vandesompele J, De Preter K, Pattyn F, Poppe B, et al. (2002). Accurate normalization of real-time quantitative RT-PCR data by geometric averaging of multiple internal control genes. Genome Biol. 3: RESEARCH0034.

von Mering C, Krause R, Snel B, Cornell M, et al. (2002). Comparative assessment of large-scale data sets of proteinprotein interactions. Nature 417: 399-403. 